\title{
Canada's support lags for research on Zika
}

$\mathrm{D}$ espite recent federal government announcements of $\$ 3$ million for research into mosquito-borne Zika virus, scientists are disappointed they only provide for "approximately three grants."

The amount devoted to Zika research and development on a percapita basis in Canada totals about $\$ 0.08$ per person, less than in the United Kingdom (about $\$ 0.11$ per person) or the United States (likely to be at least $\$ 0.94$ per person), a reminder that Canada's science funders lag behind on emerging infectious diseases, as with Ebola. Canada is, however, spending more than the European Union (about $\$ 0.03$ per person).

Canada's call for proposals for the new research dollars was announced May 6, well after funding announcements in the three comparable jurisdictions.

Earlier this year, the UK promised $\$ 7.5$ million, the EU announced $\$ 14.8$ million and the US, has so far provided over US\$230 million for Zika research. On May 11, the government announced it was also giving $\$ 1.95$ million in humanitarian assistance for countries most affected by the outbreak.

Many questions remain about how to prevent the spread of Zika, how to diagnose it and how it leads to congenital microcephaly in newborns and the autoimmune condition Guillain-Barré syndrome in adults. These require critical research in the short term, according to an international group of 52 experts who set research priorities in March for the Pan American Health Organization. The group included three people from the Public Health Agency of Canada - including its director and a director from the Canadian Institutes of Health Research (CIHR).

Given the federal government's slow response, some Canadian researchers sought funding beyond our borders. Sponsorship by the US Centers for Disease Control (CDC) origi-

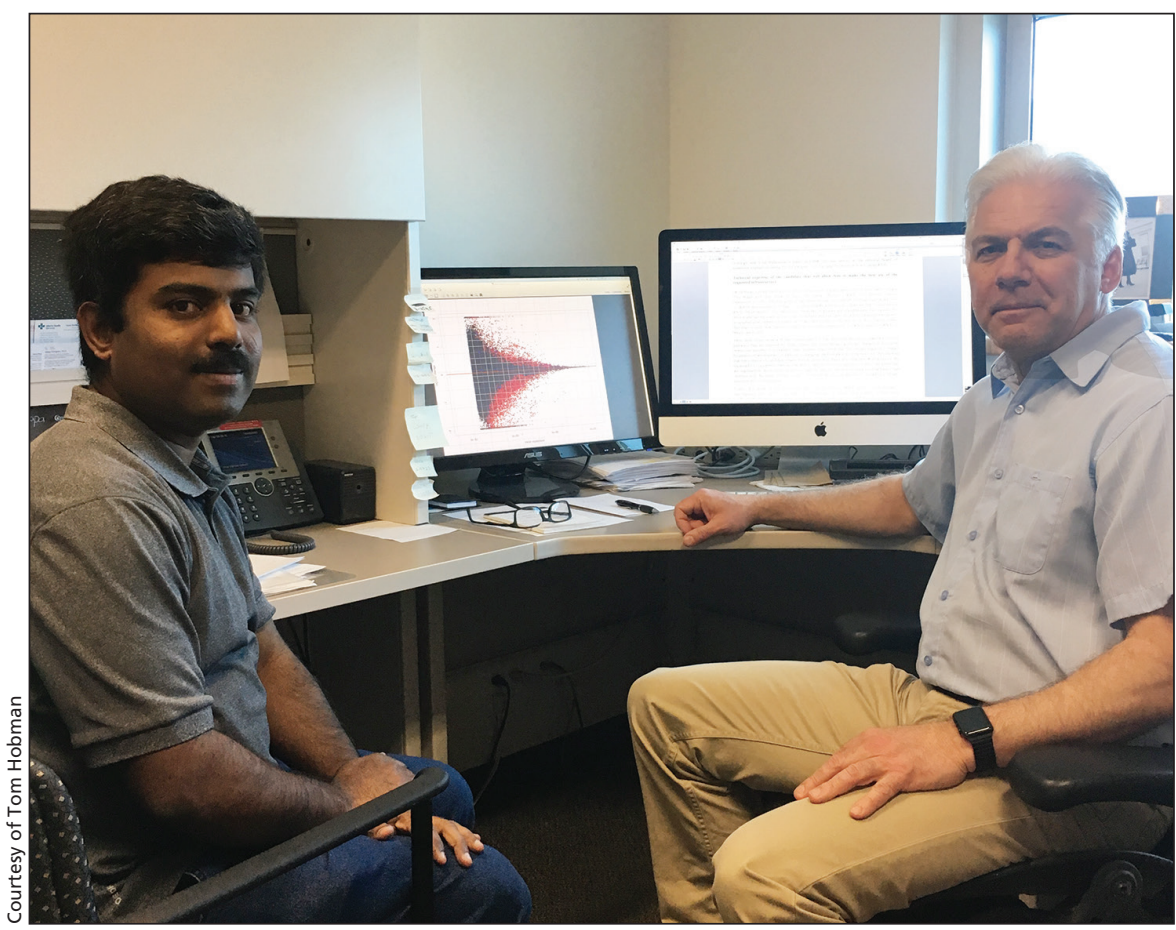

Tom Hobman (right), Canada Research Chair in RNA Viruses at the University of Alberta, struggled to find funding for his Zika project team, including colleague Dr. Anil Kumar.

nally allowed Toronto virus tracker Dr. Kamran Khan to study the Zika virus before it was even clearly linked to an outbreak. His 40-person team, Blue Dot, has honed a process for predicting an outbreak's spread by combing through data from the airline industry on more than 3 billion passengers, and matching them with population reports and mosquito and climate information.

When the rare condition of microcephaly in newborns was tied to Brazilian women infected with Zika while pregnant, Khan and his team were the first to forecast where the virus would be next. Today, his company is mapping out where Zika will strike in the summer and fall — still funded by the CDC.

Researchers at at least 10 other Canadian labs toil on despite scant and uncertain resources. Among them is virologist Tom Hobman of the University of Alberta in Edmonton, who is working on a rapid diagnostic test for Zika and a test for Zika-immunity in individuals exposed to the virus. Some team members are building clones of the virus that could be used to screen possible drug treatments. It has been a slog for Hobman to finance these initiatives. He was hopeful in December, when a CIHR official contacted him about the possibility of Zika-specific funding, but he heard nothing further.

Hobman's team has one-year funding from the University of Alberta's Li Ka Shing Institute of Virology and Alberta's Women and Children's Health Research Institute. He's also applied for a CIHR project grant and a federal Centres of Excellence grant.

Marc Ouellette, director of the CIHR's Institute on Infection and Immunity, and Dominique Charron, who leads the International Development Research Centre (IDRC) Agriculture and Environment program, are part of an international funding network that aims to enable a research response within 48 hours of a major outbreak: 
the Global Research Collaboration for Infectious Disease Preparedness.

Both were at its meeting in Washington in March to plan urgent research on Zika. Soon after, Ouellette told CMAJ that a number of different federal agencies were working to develop a research funding opportunity and he hoped it would be linked with the EU's call for research proposals to reduce duplication of effort. But when the EU call went out in March, Canada wasn't ready.

The long wait for more limited dol- lars is part of a long-standing pattern. "Canada's an underachiever" in research and development funding for the world's neglected diseases, says Dr. Peter Hotez, a United States science envoy and dean of the National School of Tropical Medicine at Baylor College of Medicine in Houston. In a report that ranks public funders of neglected diseases, Canada comes 10th, behind not only the US, the UK and the EU, but also India, Switzerland and the Netherlands. And when the figures are tallied as a proportion of gross domestic product (GDP), Canada does not make the top 12 .

As for the Zika virus, "Mosquitos don't stop at borders," says Tim Geary, director of McGill University's Institute of Parasitology. Zika is now in 60 countries and continuing to spread; Canadians are not immune. "As Canadians, where do we go?" asks Hobman. "To these warm areas where the virus is going to be circulating." - Miriam Shuchman MD, Toronto, Ont.

CMAJ 2016. DOI:10.1503/cmaj.109-5284 